\title{
lon chromatographic and voltammetric determination of heavy metals in soils. Comparison with atomic emission spectroscopy
}

\author{
P. Gunkel ${ }^{1}$, B. Fabre ${ }^{1 *}$, G. Prado ${ }^{1}$ and J.Y. Baliteau ${ }^{2}$ \\ ${ }^{1}$ Université de Haute Alsace, Laboratoire Gestion des Risques et Environnement, \\ 25, rue de Chemnitz, 68200 Mulhouse, France \\ ${ }^{2}$ SADEF, rue de la Station, 68700 Aspach le Bas, France
}

\begin{abstract}
This work deals with the comparison between three analytical techniques for the total contents analysis of heavy metals in agricultural soils polluted by copper. The soils samples are digested to clear solutions using a mixture of perchloric and hydrofluoric acids. The metals studied are copper, lead, cadmium, nickel, cobalt, zinc and manganese. Soil solutions are complex matrices and the analytical techniques investigated are ion chromatography (IC), Anodic Stripping Voltammetry (ASV) or Adsorptive Stripping Voltammetry (AdSV) and Inductively Coupled Plasma Atomic Emission Spectroscopy (ICP-AES), or graphite furnace atomic absorption spectroscopy (AAS). The use of ion chromatography as analytical technique is possible using two different eluents: PDCA for the determination of zinc, cobalt and manganese and oxalic acid for the analysis of copper, nickel and manganese. Without any enrichment process we can obtain very good agreement results between ICP-AES and IC for Cu ${ }^{2+}$, $\mathrm{Mn}^{2+}, \mathrm{Zn}^{2+}$ and $\mathrm{Ni}^{2+}$. Good correlation are obtained between ASV and ICP-AES or AAS for $\mathrm{Cd}^{2+}, \mathrm{Pb}^{2+}$ and $\mathrm{Zn}^{2+}$ and between AdSV and ICP-AES for $\mathrm{Ni}^{2+}$. No good agreement is found between IC or AdSV on the one hand and ICP-AES on the other hand for cobalt.
\end{abstract}

Keywords. Ion Chromatography - Voltammetry - Atomic Emission Spectroscopy - Soils Analysis - Heavy Metals.

\section{Introduction}

It is widely known that the analysis of trace elements is tricky and that the results obtained often vary according to the analytical technique chosen.

The aim of this paper is to compare different analytical techniques, a spectroscopic, an electrochemical and a chromatographic one to determine total heavy metals concentrations in soils and to establish a correlation between these three techniques even though soil solutions are complex matrices providing a lot of interference problems.

Atomic emission spectroscopy is the method of reference for heavy metals concentrations analysis. This analytical technique is employed for multi-element analysis and is suitable for a routine measuring out [1]. Polarographic methods are commonly used because of their very low detection limits but still, they are time consuming. Ion chromatographic techniques are generally described in the literature for heavy metals analysis in simple matrix like water but no papers were found for complex matrices like soils or sediments.

The first part of this paper presents the apparatus used and the analytical reagents. The second section describes the experimental results obtained with ion chromatography, anodic stripping voltammetry and atomic emission spectroscopy. The last section presents a discussion and a comparison of the results obtained with the different methods for each heavy metal studied.

\section{Materials and methods}

\section{Ion Chromatography}

The measurements are carried out on a DIONEX DX 500 system which is composed of a peristaltic pump GP 40, a pre column CG5A, a CS5A column and a UV-Visible detector AD20. The CS5A column is compatible with $\mathrm{pH} 0$ to 14 , allowing the analysis of acid digested soil solutions. Two different Dionex eluents are used, the Met Pac PDCA and the Met Pac Oxalic Acid. The first one is a pyridine-2,6 dicarboxylic acid (PDCA) eluent which is a strong complexing agent that separates the metal ion complexes by anion exchange. The second one is an oxalic acid eluent which is a moderate strength complexing agent that separates the metals by a mixed mode mechanism, anion exchange for metals complexed with oxalic acid and cation exchange for free metals. The detection is accomplished by visible absorbance after post column complexation between heavy metals and a post column reagent. The post column reagent is prepared with $30 \mathrm{mg}$ of 4-(2pyridylazo)resorcinol

*Correspondence and reprints.

Received April, 2, 1999; revised September 9, 1999; accepted September 14, 1999. 


\section{Original articles}

(PAR) in $250 \mathrm{~mL}$ Met Pac PAR post column reagent (Dionex). This reagent is the most widely used for the detection of transition metals and lanthanides [2-3].

The detector wavelength is $530 \mathrm{~nm}$. The sample loop volume is $50 \mu \mathrm{L}$, the eluent flow rate is fixed at $1.2 \mathrm{~mL} / \mathrm{min}$ and the post column reagent flow rate at $0.6 \mathrm{~mL} / \mathrm{min}$. The column backpressure is 1700 psi. Heavy metals concentrations are given in relation to calibration curves. Results are optimised by the software Peaknet 4.30 (Dionex).

The isocratic analytical separations of heavy metals requires less than 15 minutes.

\section{Voltammetry: Anodic Stripping Voltammetry (ASV) and Adsorptive Stripping Voltammetry (AdSV)}

The apparatus consists in a Radiometer MDE 150 polarographic stand, a Radiometer POL 150 as electric system and a software Trace Master 5 (Radiometer). The polarographic cell has the three electrode system: a dropping mercury electrode (working electrode) Radiometer A31K004, a silver/ silver chloride (3 $\mathrm{M}$ potassium chloride) reference electrode Radiometer B18C003 and a platinum auxiliary electrode Radiometer B18C002. A hanging mercury drop electrode (HMDE) is used in the differential pulse mode. The analysis of $\mathrm{Zn}^{2+}, \mathrm{Pb}^{2+}, \mathrm{Cd}^{2+}$ and $\mathrm{Cu}^{2+}$ was performed in $\mathrm{KCl} 0.1 \mathrm{M}$ by anodic stripping voltammetry. One $\mathrm{mL}$ of soil sample is diluted in $7 \mathrm{~mL}$ of supporting electrolyte. The $\mathrm{pH}$ in the polarographic cell is 1.5. Nickel and cobalt measuring out are monitored by Adsorptive Stripping Voltammetry (AdSV) [4]. The difference between ASV and AdSV is situated at the preconcentration step during which a metal complex is realised with a ligand and is adsorbed onto the electrode solution interface [4]. The response of AdSV is proportional to the concentration of the adsorbed complex (metal - ligand). The procedure involves adsorption of nickel and cobalt onto the HMDE as dimethylglyoximates ( $\mathrm{pH}=9.3)$ followed by a cathodic scan. Dimethylglyoxime (DMG) is the complexing agent of choice allowing very low detection of $\mathrm{Ni}^{2+}\left(1 \mu \mathrm{g} . \mathrm{L}^{-1}\right)$ and $\mathrm{Co}^{2+}\left(0.4 \mu \mathrm{g} . \mathrm{L}^{-1}\right)$ in the polarographic cell [5-6]. $100 \mu \mathrm{L}$ of soil sample is diluted in $7 \mathrm{~mL}$ of $\mathrm{NH}_{3} / \mathrm{NH}_{4} \mathrm{Cl} 1 \mathrm{M}$ and $70 \mu \mathrm{L}$ of DMG $0.1 \mathrm{M}$. The DMG solution is prepared daily by dissolution in ethanol. Cobalt and nickel are determined simultaneously. The experimental conditions for the polarographic procedures are summarised in table I.
At the start of each experiment all solutions are deoxygenated 15 minutes with nitrogen and a flow of nitrogen is maintained during the experiment to prevent oxygen interference. Heavy metals concentrations are determined by a three points standard addition method to avoid matrix effects. After each standard addition, the solution is stirred and deoxygenated for 2 minutes before applying the polarographic procedure again. Electrodeposition times are given in table I.

\section{Inductive Coupled Plasma - Atomic Emission Spectroscopy (ICP-AES) and Atomic Absorption Spectroscopy (AAS)}

The analysis of $\mathrm{Cu}^{2+}, \mathrm{Pb}^{2+}, \mathrm{Ni}^{2+}, \mathrm{Co}^{2+}, \mathrm{Zn}^{2+}$ and $\mathrm{Mn}^{2+}$ were carried out with a Varian ICP - AES Liberty II. Operating conditions are given table II. Similar lines and orders have been used by other authors [1,7]. Cadmium concentrations are determined by a graphite furnace atomic absorption spectroscopy Varian Spectra AA-400-Zeeman graphite tube atomizer.

Heavy metals concentrations are given in relation to calibration curves. Standards are enriched with calcium, iron, aluminium to simulate matrix effects. Measures are realised by axial aiming. Samples are injected by pneumatic nebulizer.

\section{Soils}

Five types of soils are collected in april 1998: an agricultural soil (soil A), the same agricultural soil enriched with copper $\left(\mathrm{CuSO}_{4}\right)$ in $1992(300 \mathrm{~kg} / \mathrm{ha})$ (soil B), the same soil enriched with copper and organic matter (30 t/ha) (Soil C),

Table II. Spectral lines employed in ICP-AES.

\begin{tabular}{lcc}
\hline Element & Line $(\mathrm{nm})$ & Order \\
\hline $\mathrm{Co}^{2+}$ & 228.616 & 3 \\
$\mathrm{Cu}^{2+}$ & 327.396 & 2 \\
$\mathrm{Mn}^{2+}$ & 257.610 & 3 \\
$\mathrm{Ni}^{2+}$ & 221.647 & 3 \\
$\mathrm{~Pb}^{2+}$ & 220.353 & 3 \\
$\mathrm{Zn}^{2+}$ & 213.856 & 3 \\
\hline
\end{tabular}

Table I. Experimental conditions for the polarographic measurements

\begin{tabular}{lcccc}
\hline & Applied potential range $(\mathrm{mV})$ & Standard addition & $E_{1 / 2}(m V)$ & Deposition ${ }^{(1)}$ or adsorption ${ }^{(2)}$ Time $(s)$ \\
\hline Zinc & $-1050 /-800$ & $15 \mu \mathrm{L}$ at $10^{-4} \mathrm{M}$ & -960 & $120(1)$ \\
Cadmium & $-650 /-450$ & $8 \mu \mathrm{L}$ at $10^{-6} \mathrm{M}$ & -555 & $900 \ldots .(1)$ \\
Lead & $-450 /-250$ & $15 \mu \mathrm{L}$ at $10^{-5} \mathrm{M}$ & -355 & $120 \ldots .(1)$ \\
Copper & $-250 /+70$ & $15 \mu \mathrm{L}$ at $10^{-4} \mathrm{M}$ & -65 & $120 \ldots .(1)$ \\
Nickel & $-750 /-1200$ & $10 \mu \mathrm{L}$ at $10^{-4} \mathrm{M}$ & -940 \\
Cobalt & $-750 /-1200$ & $7 \mu \mathrm{L}$ at $10^{-5} \mathrm{M}$ & -1125 & $30 \ldots \ldots(2)$ \\
& & & $30 \ldots . .(2)$ \\
\hline
\end{tabular}


Table III. Soil properties.

\begin{tabular}{lccccccc}
\hline clay $\%$ & Fine Silt $\%$ & Coarse Silt $\%$ & Fine Sand $\%$ & Coarse Sand \% & $p H \mathrm{H}_{2} \mathrm{O}$ & CEC meq/kg & Organic matter \% \\
\hline 16.6 & 30.7 & 34.4 & 15.1 & 2 & 5.8 & 96 & 2 \\
\hline
\end{tabular}

enriched with copper and lime (4 t/ha) (Soil D), and enriched with copper-organic matter and lime (soil E). For each category of soils, 3 depth fractions are collected: at $0-10 \mathrm{~cm}$ (A1, B1,..), $10-20 \mathrm{~cm}(\mathrm{~A} 2, \mathrm{~B} 2 \ldots)$ and $20-30 \mathrm{~cm}$ $(\mathrm{A} 3, \mathrm{~B} 3, \ldots)$. The soils are air-dried and sieved $(<250 \mu \mathrm{m})$. Physical and chemical properties of the natural soil are presented in table III and are determined using standard methods. These soils are characterised by a high content in silt (69 \%) while clay and sand percentages are similar. These soils have poor organic matter content. $\mathrm{pH}$ values are contained between 5.8 (agricultural soil) to 6.3 (soil enriched with lime and organic matter) [8].

Chemical analysis of heavy metals in soils requires matrix destruction, particularly of siliceous materials. This can be ensured by using HF [9].

$250 \mathrm{mg}$ of these different soils are digested with $\mathrm{HF}$ $(5 \mathrm{~mL})$ and $\mathrm{HClO}_{4}(1.5 \mathrm{~mL})$ in accordance with AFNOR standard NFX 31-147 procedure [10]. Because of the poor organic matter content, the pretreatment step with $\mathrm{HNO}_{3}$ is cut out. Aliquots were taken up in hydrochloric acid $(1 \mathrm{~mL})$ and completed at $50 \mathrm{~mL}$ with de-ionised water for analysis.

\section{Reagents}

All reagents were of analytical Fluka grade purity: $\mathrm{CuSO}_{4}, 3$ $\mathrm{H}_{2} \mathrm{O} ; \mathrm{Cd}\left(\mathrm{NO}_{3}\right)_{2}, 4 \mathrm{H}_{2} \mathrm{O} ; \mathrm{CoSO}_{4}, 7 \mathrm{H}_{2} \mathrm{O}$; $\mathrm{NiSO}_{4}, 6 \mathrm{H}_{2} \mathrm{O}$; $\mathrm{Pd}\left(\mathrm{NO}_{3}\right)_{2}, 6 \mathrm{H}_{2} \mathrm{O} ; \mathrm{Zn}\left(\mathrm{NO}_{3}\right)_{2}, 6 \mathrm{H}_{2} \mathrm{O} ; \mathrm{Mn}\left(\mathrm{NO}_{3}\right)_{2}, 4 \mathrm{H}_{2} \mathrm{O}$. DMG $(0.1 \mathrm{M})$ was prepared by dissolving an amount in ethanol [3]. Stock solutions $\left(10^{-2} \mathrm{M}\right)$ of each heavy metal studied are prepared and required standards are prepared daily by appropriate dilution of the stock solution.

With the aim of avoiding any contamination, all glassware is rinsed with concentrated nitric acid and with deionised water before use. Water is purified with a Milli-Qsystem (MILLIPORE) and has a specific resistance of 18 megohms-cm. This water is used for all sample and solution preparations.

\section{Results and discussion for the two analytical methods tested}

\section{Ion Chromatography}

As indicated before, it is necessary to use two eluent systems to separate all the peaks of the heavy metals studied as we can see in figures 1 (PDCA) and 2 (oxalic acid). Both eluents give complementary results. Retention times are given in table IV. With PDCA, $\mathrm{Cu}^{2+}, \mathrm{Fe}^{3+}, \mathrm{Ni}^{2+}, \mathrm{Zn}^{2+}, \mathrm{Co}^{2+}$

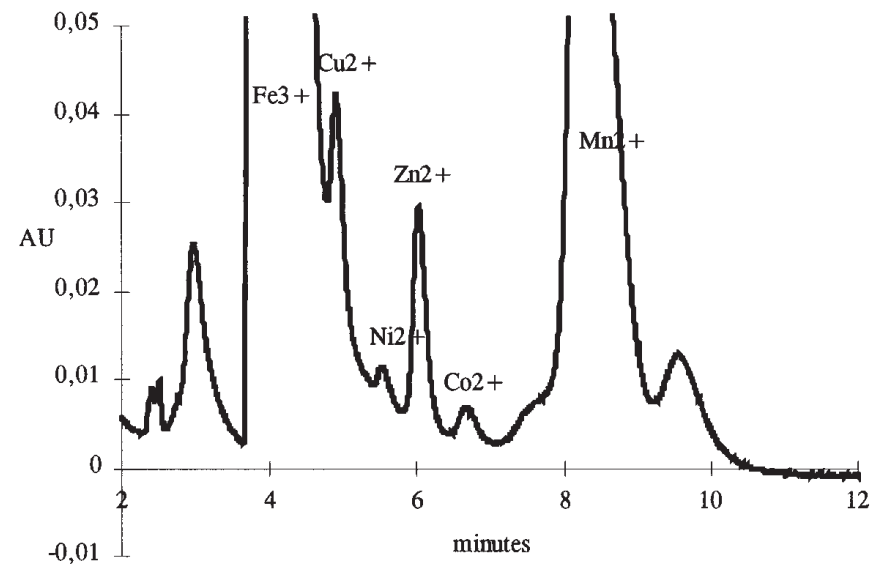

Fig 1. Ion chromatographic separation using PDCA. Soil B3.

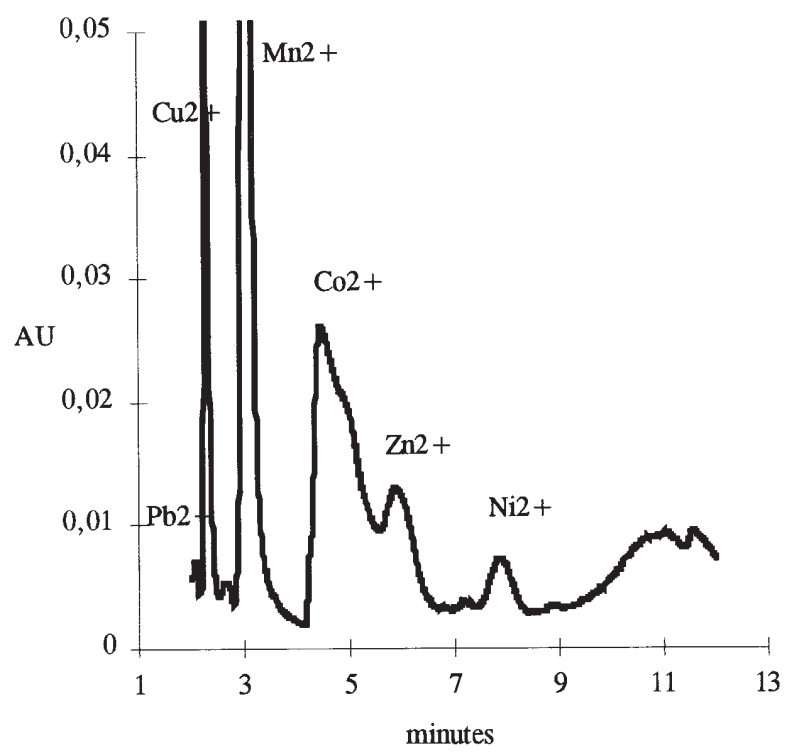

Fig 2. Ion chromatographic separation using oxalic acid. Soil B3.

and $\mathrm{Mn}^{2+}$ are eluted. Lead and cadmium elute as well with PDCA but under these conditions, they are so strongly bound to the PDCA complexing agent that they are not sensitively detected by the post column reagent. This eluent presents also the advantage to separate manganese and 
Table IV. Retention times (minutes) of some elements using ion chromatography with PDCA and oxalic acid as eluents.

\begin{tabular}{lcc}
\hline Metals & PDCA & Oxalic acid \\
\hline $\mathrm{Pb}^{2+}$ & nd & 1.9 \\
$\mathrm{Fe}^{3+}$ & 3.7 & not eluted \\
$\mathrm{Cu}^{2+}$ & 4.7 & 2.2 \\
$\mathrm{Ni}^{2+}$ & 5.3 & 7.7 \\
$\mathrm{Zn}^{2+}$ & 5.8 & 5.7 \\
$\mathrm{Co}^{2+}$ & 6.4 & 4.0 \\
$\mathrm{Mn}^{2+}$ & 8.1 & 3.0 \\
\hline
\end{tabular}

cadmium but in regard to the reasons mentioned above cadmium is not detected in our samples. As we can see, with the PDCA eluent, the ferric concentration is very high compared to other metals and reaches about $25000 \mathrm{mg} / \mathrm{kg}$ (125 mg. $\mathrm{L}^{-1}$ ) while other metals have concentrations close to $50 \mathrm{mg} / \mathrm{kg}\left(0.25 \mathrm{mg} . \mathrm{L}^{-1}\right)$ (excepted manganese). Therefore the ferric peak disturbs copper and nickel peaks integration. Dilution is not possible because of limit detections problems and a gradient with water was tested without success.

With the oxalate eluent, which is a moderate strength complexing agent, it is possible to detect lead and cadmium. But these two metals can't be measured in our samples. Indeed, cadmium co-elute with manganese. But we admit that the presence of cadmium doesn't over-estimate manganese concentration because manganese is much more concentrated $(700 \mathrm{mg} / \mathrm{kg})$ than cadmium $(0.2 \mathrm{mg} / \mathrm{kg})$ in soils. And lead's peak is not well separated therefore lead can't be measured by ion chromatography in our soil samples. Copper and nickel are analysed with oxalic acid.

$\mathrm{Fe}^{3+}$, not eluted, disrupts the baseline and a column cleaning with PDCA is often required to remove the excess of $\mathrm{Fe}^{3+}$. We also encounter important matrix effects as shown on figure 2. Interferences due to the sample matrix is common in ion chromatography especially when a large quantity of alkali and alkaline earth metals are present [11]. Therefore the use of the both eluent systems is necessary to obtain all the elements with different retention times [8], they are complementary. This disrupting of the baseline doesn't allow measuring out exactly cobalt and lead concentrations with this technique as we could see that in the following discussion with the comparison with polarographic and atomic techniques.

\section{Anodic stripping voltammetry and adsorptive stripping voltammetry}

With the Anodic Stripping Voltammetry method, we can easily detect $\mathrm{Zn}^{2+}, \mathrm{Cd}^{2+}, \mathrm{Pb}^{2+}$ and $\mathrm{Cu}^{2+}$ at very low concentrations with very good correlation coefficients (Fig. 3). Same results were obtained by other teams [12-14]. Each transition metal is measured only in its corresponding window to avoid interferences and intermetallic complexes formation. Zinc, cadmium lead and copper analysis is performed with $1 \mathrm{~mL}$ of sample in $7 \mathrm{~mL}$ of $\mathrm{KCl} 0.1 \mathrm{M}$. Such a dilution is

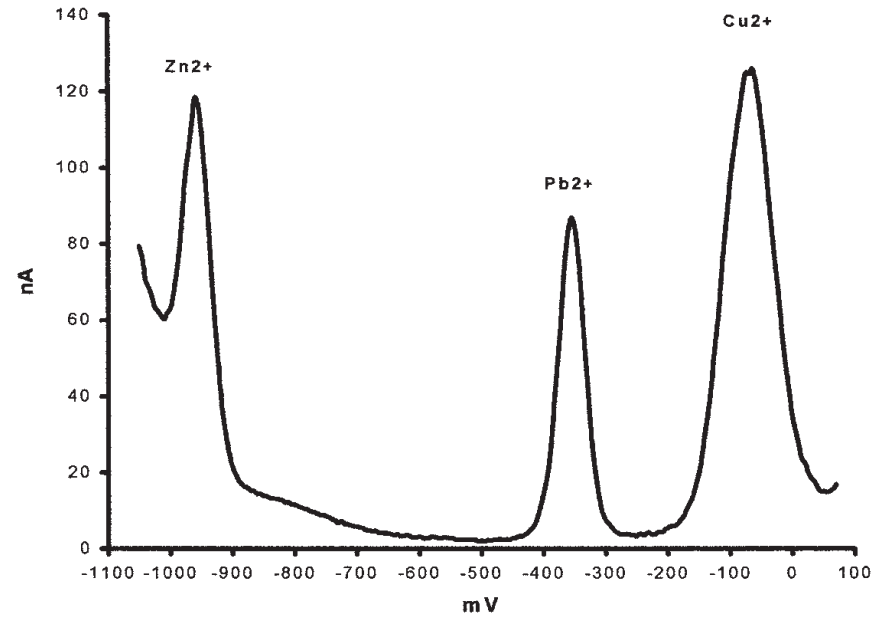

Fig 3. Anodic stripping voltammogram. $\mathrm{Zn}^{2+}, \mathrm{Pb}^{2+}, \mathrm{Cu}^{2+}$ in $\mathrm{KCl}$ 0.1 M. Soil C1.

necessary to increase the $\mathrm{pH}$ in the polarographic cell at 1.5 and to avoid capillary block up.

No problems are encountered for lead and zinc analysis. $\mathrm{Zn}^{2+}$ rate was high enough to stand higher than the negative wall limits (at $-1050 \mathrm{mV}$ ) that arises from the reduction of water to give hydrogen [15]. Cadmium analysis needs a long deposition time ( 15 minutes) because of it's very low rate $\left(0.2 \mathrm{mg} / \mathrm{kg}\right.$ corresponding to $\left.1 \mu \mathrm{g} . \mathrm{L}^{-1}\right)$.

For nickel and cobalt analysis (Fig. 4), the largest separation between the cobalt and nickel peaks requires a $1 \mathrm{M}$

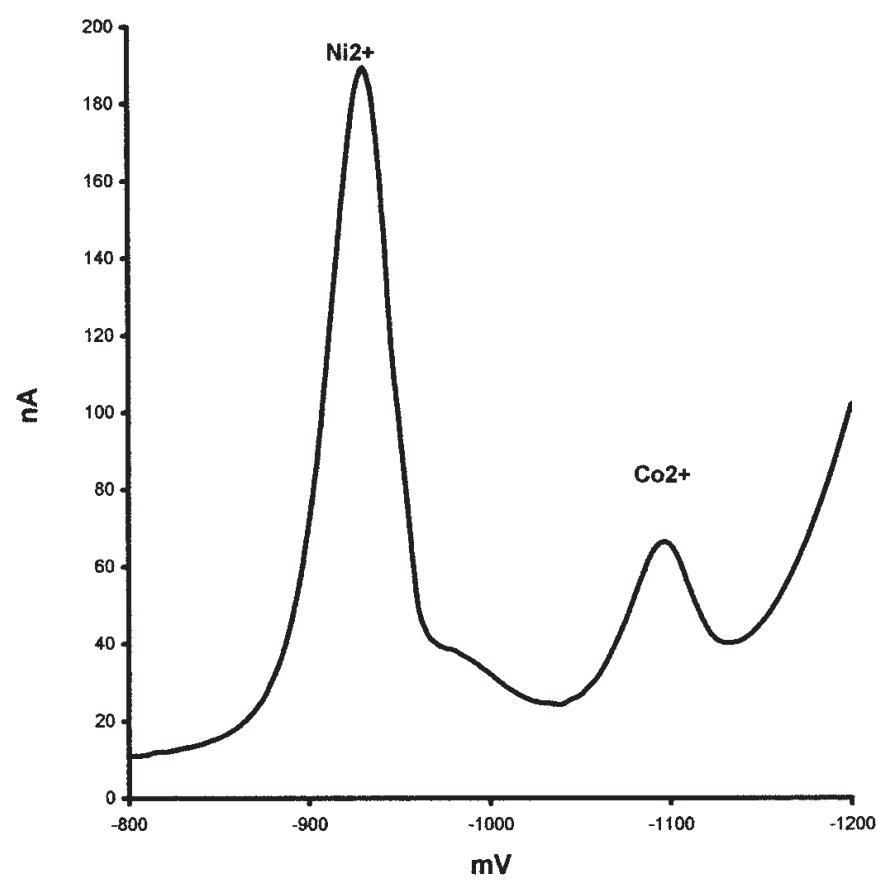

Fig 4. Adsorptive stripping voltammogram : $\mathrm{Ni}^{2+}$ and $\mathrm{Co}^{2+}$ in $\mathrm{NH}_{3} / \mathrm{NH}_{4} \mathrm{Cl} 1 \mathrm{M}+$ DMG 0.1 M. Soil A3. 
buffer solution [5]. The concentration of DMG used is also a parameter of importance. The cobalt peak increases substantially with increasing $\mathrm{DMGH}_{2}$ concentration while the nickel peak decreases slightly as the concentration of the chelating agent increases. On the other hand, the resolution between nickel and cobalt peak decreases as the $\mathrm{DMGH}_{2}$ concentration increases. Best results and a linear response to standard addition are obtained for a concentration of $8.10^{-4}$ $\mathrm{M}$ for $\mathrm{DMGH}_{2}$ in the polarographic cell.

\section{Comparisons between voltammetric, ion chromatographic and ICP-AES determinations}

\section{Copper and zinc}

For copper, a very good agreement is found between ion chromatography with the oxalic acid eluent and atomic emission spectroscopy (Table V). Nevertheless ASV measurements give concentrations 2.5 to 3 times higher than the ICP-AES and IC results. This can be explained because of the high rate of iron in soil samples. Indeed with potassium chloride as a supporting electrolyte, the waves for $\mathrm{Fe}^{3+}$ and $\mathrm{Cu}^{2+}$ interfere with one another [15].

For zinc, the three analytical techniques give similar results.

\section{Lead}

About lead, we obtain a good correlation between ASV and ICP - AES results (Table VI). Ion chromatography measurements weren't exploitable. Indeed $\mathrm{Pb}^{2+}$ is detected with the oxalate eluent system but the peak is not correctly resolved and the lead amount is not sufficient to stand higher than the baseline noise. We have baseline perturbations for the first retention times.

\section{Cadmium}

This metal is in very low concentration in our samples, therefore only two methods were able to detect it : ASV and AAS. Both analytical techniques give similar results (Table VI). Cadmium co-elutes with manganese in oxalic acid eluent and is not detected with PDCA without enrichment process.

\section{Manganese}

Manganese is only analysed by ICP - AES and ion chromatography with the PDCA eluent system and with the oxalic acid eluent system (Table VI). The first eluent system named gives concentrations 15 to $20 \%$ lower than the results obtained by ICP -AES while the second eluent system named gives good agreements considering that manganese concentration is 3000 times higher than cadmium concentration.
Table V. Results obtained by the three analytical methods for copper and zinc.

\begin{tabular}{lcccccc}
\hline \multicolumn{3}{c}{ Samples } & \multicolumn{3}{c}{ Copper $(\mathrm{mg} / \mathrm{kg})$} & \multicolumn{4}{c}{$z i n c(\mathrm{mg} / \mathrm{kg})$} \\
& IC OA & ASV & ICP-AES & IC PDCA & ASV & ICP-AES \\
\hline A1 & 25.5 & 64.7 & 25.2 & 54.6 & 61.7 & 53.0 \\
A2 & 22.7 & 35.5 & 23.9 & 56.9 & 48.9 & 52.6 \\
A3 & 23.7 & 80.9 & 23.7 & 55.5 & 54.2 & 52.5 \\
B1 & 62.8 & 199.0 & 64.1 & 65.7 & 63.3 & 59.5 \\
B2 & 73.8 & 189.5 & 72.8 & 66.5 & 57.1 & 63.8 \\
B3 & 65.4 & 174.2 & 67.2 & 68.7 & 58.5 & 63.2 \\
C1 & 66.7 & 157.1 & 68.6 & 56.3 & 47.4 & 52.2 \\
C2 & 67.7 & 201.4 & 71.4 & 56.5 & 50.3 & 55.2 \\
C3 & 69.1 & 172.8 & 68.4 & 50.1 & 48.2 & 53.3 \\
D1 & 91.5 & 231.7 & 91.1 & 54.4 & 54.6 & 51.3 \\
D2 & 81.8 & 225.8 & 88.0 & 60.5 & 52.0 & 52.6 \\
D3 & 71.4 & 152.1 & 77.5 & 60.7 & 51.2 & 51.4 \\
E1 & 54.4 & 168.2 & 60.9 & 59.5 & 57.4 & 57.9 \\
E2 & 90.4 & 255.5 & 89.9 & 63.1 & 60.6 & 61.0 \\
E3 & 69.1 & 205.7 & 73.8 & 64.0 & 57.8 & 60.8 \\
\hline
\end{tabular}

IC PDCA : ion chromatography using PDCA

IC OA : ion chromatography using oxalic acid

Table VI. Results obtained by the three analytical methods for cadmium, manganese and lead.

\begin{tabular}{lcccccccc}
\hline \multicolumn{3}{c}{ Samples } & \multicolumn{3}{c}{ cadmium } & $(\mathrm{mg} / \mathrm{kg})$ & \multicolumn{3}{c}{ manganese $(\mathrm{mg} / \mathrm{kg})$} & \multicolumn{2}{c}{ Lead $(\mathrm{mg} / \mathrm{kg})$} \\
& ASV & AAS & IC OA & IC PDCA & ICP-AES & ASV & ICP-AES \\
\hline A1 & 0.20 & 0.22 & 641 & 535 & 684 & 24.1 & 26.1 \\
A2 & 0.19 & 0.21 & 644 & 535 & 688 & 27.4 & 24.1 \\
A3 & 0.23 & 0.19 & 641 & 530 & 686 & 21.6 & 25.6 \\
B1 & 0.14 & 0.24 & 641 & 522 & 676 & 30.1 & 27.6 \\
B2 & 0.26 & 0.25 & 618 & 506 & 649 & 32.7 & 32.5 \\
B3 & 0.15 & 0.26 & 635 & 507 & 669 & 29.2 & 27.3 \\
C1 & 0.47 & 0.58 & 648 & 533 & 688 & 23.3 & 24.6 \\
C2 & 0.30 & 0.40 & 734 & 550 & 703 & 28.5 & 26.1 \\
C3 & 0.50 & 0.41 & 787 & 584 & 745 & 31.1 & 25.1 \\
D1 & 0.26 & 0.22 & 771 & 552 & 689 & 24.8 & 27.3 \\
D2 & 0.29 & 0.24 & 781 & 567 & 708 & 24.6 & 26.7 \\
D3 & 0.31 & 0.21 & 720 & 571 & 696 & 28.2 & 25.6 \\
E1 & 0.37 & 0.23 & 716 & 595 & 688 & 29.5 & 27.2 \\
E2 & 0.29 & 0.24 & 697 & 573 & 698 & 26.5 & 27.8 \\
E3 & 0.28 & 0.22 & 722 & 567 & 689 & 29.2 & 27.6 \\
& & & & & & & \\
\hline
\end{tabular}

IC PDCA : ion chromatography using PDCA

IC OA : ion chromatography using oxalic acid

\section{Nickel and Cobalt}

\section{Nickel}

The eluent of choice in view of the matrix effect in ion chromatography is the oxalic acid eluent. Very good agreement is found between ion chromatography and ICP-AES (Table VII). Results are similar as well with AdSV technique, but just a little bit more unsettled because of the 


\section{Original articles}

Table VII. Results obtained by the three analytical methods for nickel and cobalt.

Samples nickel $(\mathrm{mg} / \mathrm{kg}) \quad$ cobalt $(\mathrm{mg} / \mathrm{kg})$
IC OA AdSV ICP-AES IC PDCA AdSV ICP-AES

\begin{tabular}{lcccccc}
\hline A1 & 25.5 & 26.2 & 25.9 & 6 & 5.5 & 11.8 \\
A2 & 24.5 & 31.4 & 26.6 & 5.1 & 3.2 & 11.9 \\
A3 & 25.1 & 29.9 & 26.6 & 5.4 & 6.3 & 12.6 \\
B1 & 25.6 & 20.1 & 27.7 & 5.2 & 4.5 & 12.4 \\
B2 & 26.7 & 27.2 & 28.4 & 4.9 & 7.9 & 12.0 \\
B3 & 24.3 & 26.2 & 28.3 & 6.5 & 7.4 & 12.2 \\
C1 & 25.4 & 27.0 & 25.4 & 7.3 & 8.2 & 12.2 \\
C2 & 25.1 & 23.7 & 26.7 & & 9.2 & 12.9 \\
C3 & 25.4 & 24.2 & 26.0 & & 8.5 & 12.8 \\
D1 & 24 & 20.1 & 25.6 & & 6.9 & 12.3 \\
D2 & 22.8 & 20.5 & 26.5 & & 6.1 & 12.7 \\
D3 & 29.3 & 19.5 & 25.5 & 5.9 & 5.6 & 12.3 \\
E1 & 23.5 & 25.7 & 27.6 & 5.5 & 7 & 12.5 \\
E2 & 26.3 & 18.2 & 28.8 & 4.2 & 5.6 & 13.1 \\
E3 & 27.9 & 29.6 & 29.0 & 2.9 & 10.5 & 13.1 \\
\hline
\end{tabular}

IC PDCA : ion chromatography using PDCA

IC OA : ion chromatography using oxalic acid

presence of nickel in the blank. The current of the blank signal is $60 \mathrm{nA}$ against $180 \mathrm{nA}$ with the sample signal (Fig. 4).

\section{Cobalt}

Ion chromatography analysis of cobalt is performed with the PDCA eluent. Both techniques, ion chromatography and AdSV give a cobalt rate nearly reduced by half compared to ICP-AES (Table VII). Further investigations are necessary to explain such a difference.

\section{Conclusion}

Ion chromatography offers the advantage to reveal in one injection the presence of several heavy metals in the sample. And this technique is accurate on approval to chose the appropriate eluent and to take care of matrix interferences.
Using ASV, a long time is required for complete electrodeposition. This very long time is not a great interest for a routine method. But ASV or AdSV is inescapable techniques for $\mathrm{ppb}$ detection limits without enrichment process.

On the contrary, with IC or ICP - AES determinations, it is possible to have many heavy metals detected in a short time, with good agreement between the two techniques excepted for cadmium which has a low level and for cobalt that doesn't give the same results with these two techniques.

\section{References}

1. Fournier, J.-B.; Hirsch, O.; Martin, G.J. Analusis 1998, 26, 2832.

2. Buchberger, W.W.; Haddad, P.R. Journal of Chromatography A 1997, 789, 67-83.

3. Chean, V.; Xue Li, E. Journal of Chromatography 1988, 450, 361-371.

4. Panelli, M.G.; Voulgaropoulos, A. Electroanal. 1993, 5, 355373.

5. Abeloju, S.B.; Bond, A.M. Anal. Chim. Acta 1984, 164, 181194.

6. Baxter, L.A.M.; Bodbrowski, A.; Bond, A.M.; Heath, G.A.; Paul, R.L.; Mrzijak, R.; Zarebski, J. Anal. Chem. 1998, 70, 1312 - 1323.

7. Petrucci, G.; Van Loon, J.C. Fresenius Z. Anal. Chem. 1987, 326, 345-349.

8. Fabre, B.; Gunkel, P.; Baliteau, J.-Y. in Science et technologie : Regards croisés; Actes CNRIUT'99; L'Harmattan: Paris, 1999, pp 333-341.

9. Nadkarni, R.A. Anal. Chem. 1984, 56, 2233-2237.

10. AFNOR, Norme NFX 31-147, 1996.

11. Lucy, C.A .J. Chromatogr. 1998, 804, 3-15.

12. Maréchal, A.; Salaun, J.-P.; Caullet, C. Analusis 1981, 9, 333339.

13. Florence, T.M.; Mann, K.J. Anal. Chim. Acta 1987, 200, 305312.

14. Fernandez-Bobes, C.; Fernandez-Abedul, M.T.; Costa-Garcia, A. Electroanal. 1998, 10, 701-706.

15. Skoog, D.A.; West, D.M.; Holler, F.J. Fundamentals of Analytical Chemistry: Saunders College Publishing, 1992. 